\title{
Ecology as a Global Geopolitical Issue
}

\author{
YANITSKY Oleg Nikolaevich* \\ Doctor of Philosophy, Professor, Chief Researcher, Federal Center of Theoretical and Applied Sociology of the \\ Russian Academy of Sciences
}

*Corresponding Author: YANITSKY Oleg Nikolaevich, Doctor of Philosophy, Professor, Chief Researcher, Federal Center of Theoretical and Applied Sociology of the Russian Academy of Sciences, Russia.Email: oleg.yanitsky@yandex.ru

\begin{abstract}
Drawing on the study of globalization process across the world, its information-communication structure, my participation in three international projects, and my long-term experience as urban and environmental sociologist I offered the concept of the socio biotechnical system (hereafter the SBT-system) as a theoretical instrument for the study of modern geopolitical processes. The concept is based on three methodological prerequisites: problem oriented and interdisciplinary approaches, and the concept of socioecological metabolism. The majority of existing studies of geopolitics and its impact on living environment are concentrated on man-nature relationships underestimating the role of man-made environment and its 'boomerang effects.' Under the Fourth technological revolution (hereafter the TR-4) our planet is rapidly transforming into global SBT-system conditioned and structured by resource, information-communication, migration and other networks which exert impact on all spheres of a society beyond its economic and social state. These networks play an integrative role irrespectively of time-space distance between various nationstates, local communities and individuals. The role of humanities in shaping of global political agendas is shrinking. The phenomenon of the 'strength of a weakness' has emerged. Global SBT-system functions simultaneously in accordance with natural, social and technical laws. Such hybrid is inherently contradictory and risky one. The structural-functional organization of the SBT-systems has not yet been studied sufficiently, and their dynamics is hard to predict. I see such systems as a kind of a geopolitical black-box because the regularities of its functioning are still not well-understandable. The tandem of competitive human activities and the global SBT-system response is becoming an ungoverned hybrid in which the role of grassroots activism and other forms of informal activity is rapidly growing. Technological development of the most developed countries and the transnationals which maintains their geopolitical domination forces less developed countries to use such protective measures as the bribery, hacking, stealing of technological innovations and secrets, etc. In the run of such all-embracing struggle a contradiction between a declared striving for sustainable development and an actual struggle for resources and geopolitical domination of global stakeholders is strengthening. In this uncertain and contradictory conditions the developing of models of 'ideal cities' is a mean for advertising of peaceful stand of global stakeholders and their technological achievements. In sum, the new sense of ecolog yand geopolitics has emerged.
\end{abstract}

Keywords: Cities; Complexities; Ecology; Geopolitics; Globalization; Humanity; Hybrid; Interdisciplinary Studies; Metabolism; Risk; Science; The SBT-Systems; Urban Studies.

\section{INTRODUCTION}

Our world is rapidly changing. We are witnessing the emergence of tightly compressed, uncertain and all-penetrated global environment. It is a result of the shaping of global market, informationcommunication technologies, mass migration, local and regional wars, struggle for natural and human resources, and formation of such giant nation-states' conglomerates as the European Union which are struggling for relatively safe living areas. A space has been converted into time (so-called inversion effect). Therefore, the prediction made by A. Toffler about half-a-century ago came true: our planet has become a great village [Toffler 1970].

This new state of our planet I've called as sociobiotehincal system [Yanitsky 2016]. For the reason of rapidly growing replacement of natural processes and ecosystems by the SBT-systems of various nature and scale and the struggle for information, natural and human resources these systems are unstable and burdened by unintended consequences. The emergence of global SBT-system generates numerous consequences in science and practice. Many particular disciplines have lost their practical 
importance because such complex systems as the SBT-systems are needed in interdisciplinary approach that is multi-disciplinary one. The old definition of geopolitics as a relations between sea power and land power[Mackinder 1919] has become too simple and not fit to a very high and mobile complexity of structures and processes which are simultaneously take place in all spheres of human activity ranging from the Cosmic space to the Earth mantle. It doesn't mean that Mackinder's concept is wrong. On the contrary, he (followingI. G. Herder and others) showed a significance of geographical location of the nation-states for their prosperity. In the XX century the rush of the UK navies to the Falkland Islands is another confirmation of Mackinder's concept. But recently geopolitics cannot be associated with political geography because it is restricted by the analysis of relationships of relatively stable landor marine units (nation-states, their alliances, oceans and seas, etc.). It means three interrelated things. First, recently we are living in entirely new global environment, absolutely transparent and hard to predict. Second, today there are no only 'ecological' problems they are always simultaneously economic, social, political, cultural, etc. Third, any political process cannot be restricted by talks and agreements only. That is why the geopolitics as a form of flexible integrated science and political practice came to the forefront.

\section{METHOdOLOGICAL AND THEORETICAL BACKGROUND}

It has been many times pointed out that any dichotomy approach as political and research tool for understanding of rapidly globalized world is wrong. The habitual dichotomies as 'global-local', 'man — nature', 'rural—urban', 'we - they' doesn't fit to our tightly integrated world. Referring to R. Robertson's idea that 'the world should be considered as a whole' [Robertson 1990], J. Bartelson argued that the world must be comprehend 'as a single place that comprises the totality of all human relationships' [Bartelson 2000: 187]. This wholeness cannot exist without two interrelated processes: a human, resource, information and other network-like processes and visible and overt transformations implemented by metabolic exchange between natural, material and sociallyconstructed entities.In the processes of this exchange large cities play a key role. As J.-S. Boudreau and D.E. Davis stated referring to the works of R. Sennett [1970] and W. Magnusson [2011], 'critical social sciences might more fruitfully look into urban ways of life if we are to better understand the complex contemporary period' [Boudreau and Davis 2017: 160]. It means that a relational approach is a basic methodological instrument in the study of the SBT-systems of any scale and kind.As for me, as a student of grassroots initiatives and social movements from early 1990s up to now, this approach together with network and metabolic ones is my working research instruments. I'm in debt to many my foreign colleagues and especially to M. Diani, D. Della Porta and D. McAdam[Diani and McAdam 2003; Della Porta and Diani 2006].The reverse side of the same coin is the interrelated tempo-rhythms of processes in question in their past, present and future dimensions. Of course, other methods and research techniques like the case-studies, the hermeneutics or oral histories have been used. In all cases of my work I simultaneously used top-down and bottom-up approach. The last one means that situational approach is valuable as well.

In spite of world-known works of the Roma Club, the majority of modern global studies environmental issues are only mentioned but rare investigated in details [Beck 1999; Castells 1996, Robertson 1994; Urry2008 and many others].It's indicative that in mid2010s all of them turned to global warming issue but without detailed analysis of its metabolic consequences [see, for example, Urry 2011]. Nevertheless, these works have been very important for the comprehension of global environmental politics. The metabolic studies [Fisher-Kowalski and Haber 2007; Haberl et al. 2016] have been much closer to the issue in question because they have been directly interconnected with the geopolitics. Nevertheless, to my mind, the true breakthrough happened in mid2000s: the first global network-structured and empirically-grounded research project on global risks has been carried out by the World Economic Forum [The Global Risk...2016]. The project involved more than 400 experts all over the world except Russian ones.

\subsection{The Impact of Technological Revolutions on Human Environment}

The essence of any Technological Revolution (the TR) is its hybrid nature. The hybrid means that its structures and consequences are qualitatively different, contradictory and still not well investigated. Historically, the shaping of such hybrids has passed a set of phases. Initially, a man has constructed a certain technological innovation for gaining food and shelter. Then the man began to construct technical systems (arms, machines, railways, etc.) based on a set of new technologies. Politically, it 
had been the turning point because the man and social institutions that had created such hybrid systems began to use them as geopolitical instruments (maps of marine and land ways, their infrastructures, logistics, see-ports, etc.). It had been a time of the first version of global geopolitics.

By and large, the systems of maintenance and development of various geopolitical instruments, peaceful and military, had been shaped and perfected. And it was the next phase of subordination of human beings to complex socio-bio-technical systems guided by global stakeholders. After then, this all-embracing complex structure has become institutionalized and a society is becoming subordinate to it. At any phase of the technological development it brings profit to its creators and strengthening their military and political power. The manifesto of technocratic society has been written [Schwab 2016]. A threat of transformation of the 'Internet of Things' into self-regulating geopolitical entity became real. More than that, some theorists consider an artificial intellect as the potential threat to any form of life on the earth. Thus, it is a time to speculate on limits of growth of such man-made hybrid systems and their geopolitics.

The Fourth TR has passed the same phases (steps) as well. But the distinguishing feature of this TR is in its all-penetrating and all-embracing nature. A carrying structure of the Fourth TR is global information-communication system which exerts impact on all spheres of a global whole irrespectively of economic and social development of its parts (the nation-states, local communities and their infrastructures). That is, the modern information-communication system has a mighty geopolitical force irrespectively of time-space distance between various nation-states, local communities and individuals. In other words, all of us are the eye-witnesses of the phenomenon of 'inversion of space into time' and of the beginning of 'inversion' of global social organism into the Internet of Things. This is why I see necessary to develop the concept of 'hybrid systems', that is, of the abovementioned SBT-systems. These systems had emerged as a result of long-term and multisided impact of human activity on natural environment (more exactly, on the Biosphere) and numerous forms of environmental feedback. As a result, a certain 'hybrid', i.e. the system which is functioning simultaneously in accordance with natural, social and technical laws has been shaped.

Such SBT-system is inherently contradictory and risky one. I distinguish two states of any SBTsystem: A normal and critical ones. A normal state means that global SBT-system is in a state of relative equilibrium. It doesn't mean that there are no any conflicts or tensions within it. It only signifies that these tensions and conflicts don't violate this particular form of relative equilibrium. A characteristic feature of recent times is that these tensions and conflicts tend to acquire a global character. And this shift is hard to foresee for the reason that territorially-small conflict may trigger a global conflict with unintended consequences, and vice versa. A critical state means that the majority of global stakeholders, i.e. world geopolitical makers are turning into open adversaries, and a 'hybrid' war may acquire a global character with unintended consequences. It signifies two things. In modern times when the 'all is tightly interconnected with all' (B. Commoner), every local conflict has in essence regional or even global character. It also means that international institutions like the United Nations or the World Bank are not capable to cope with all local or regional conflicts. The best example of merging of the above two states is modern Syria that has become a crossroads of interests of many global and regional stakeholders.

\subsection{Metabolic Processes as an Integrating Force}

To begin with, I would remind that the concept of Russian biochemist Vernadsky of the Biosphere is based on material-energetic metabolic principle [Vernadsky, 1980: 67, 68, 213, 231-234, 239]. He underscored that united humanity has become a biochemical power, and a man as such is becoming a mighty geological force. The key processes that join these contradictory parts of the hybrid systems are metabolic ones. They are not simply the 'interactions' but transformations with various results: a merging, annihilation, mutual transformation, suppression, etc. A reducing of this variety of metabolic transformation to an energy use or exchange is an oversimplification. As well as such transformations cannot be reduced to 'man - nature' interactions. There is a lot of research of metabolic processes [Wolman 1965; Fisher-Kowalski 1997; Fisher-Kowalski and Haberl 2007; Haberl et al. 2016] but the majority of them are not taking into account a variety of transformations took part on geophysical, chemical and especially molecular levels. Social metabolism as such is never systematically had been investigated though the attempts of its study had been done dated even from the works of the fathers of the Chicago School of Social Ecology [Park et al. 1926; Park 1952]. 
An important part of the SBT-system's metabolism is a socio-ecological metabolism as such. The metabolic processes of that kind earlier happened in particular communities, cities and nation-states which have usually been territorially-fixed, and have not acquired a global scale and all-embracing character. The globalization of socio-ecological metabolism in the 3-D format and accordingly new format of geopolitics is a new phenomenon. Global socio-metabolic processes have various forms. First, it is mass migration processes which have demographic, political, social, cultural and other consequences across the world. Second, it is natural and forced changes in socio-professional structure of countries and regions which, in turn, triggers the transformations of labor market, system of education and additional (or non-stop) training as well as in the system of services and medical care. Third, it is the transformation of the globe into an all-embracing melting pot burdened with ethnic-confessional and social conflicts. Fourth, it is a threat of dispersion of endemics by means of the insects, viruses, and plants as well as by the ideologies and modes of mass behavior, etc. over the world. Finally, a scientific-and-technological potential of some global stakeholders allow them to construct artificially global socio-metabolic processes and spread them across the world by means of mass-media. Nevertheless, the humanity continues to behave in relation to its own living environment as biological species. Natural ecosystems is used by people as a space for various forms of built areas (the cities and towns, plants, infrastructures) or as the areas for an extraction and production of natural resources (an oil, gas, woods, mineral resources, etc.).

As globally-concerned authors noted, a dynamics of global system is uncertain and not predictable. Besides, it is wrong to consider the Nature as an unlimited pool of various resources only. The Biosphere is a system which laws are yet not sufficiently investigated. But the emergence of the global SBT-system is a distinguishing feature of our times. I see this system as a kind of a black-box because the regularities of competitive human activity and possible the global SBT-system responses have become an ungoverned hybrid. The structural-functional organization of global SBT-system is rather complicated, and therefore its dynamics is hard to predict. It could be only stated that the global SBT-system develops in accordance of the laws of complex systems [Keen 2008]. But their regularities are, in turn, are dependent on global-local metabolic processes which are diverse in their origin, structural-functional organization and tempo-rhythms because they are the results of numerous interactions of qualitatively different more or less socially-constructed sub-systems. Besides, in accordance of the Second theorem of K. Goedel, such sub-systems are dependent on the behavior of the SBT-system of higher level and more embracing scale, etc. Such extremely complex systems are difficult to study for one more reason: in accordance of S. Bredford and D. Zipf theorem, a necessary knowledge related to such systems is spread in numerous sources of scientific articles and public essays. In what degree metabolic processes are diverse, hardly seen and extremely dangerous both for man and nature is well illustrated by the eutrophication process of the Baikal Lake and many other lakes of Russia.

\subsection{From the Biosphere to Global SBT-System}

The shaping of global SBT-system violates evolutionary-formed balance of the Biosphere. The global SBT-system began to produce unexpected and large-scale risks which, in turn, may provoke critical and even destructive situations of local, regional and even global scale of social and geopolitical nature. It means that the process of transformation of the Biosphere into the global SBT-system raises its high-risks productivity. More than that, in modern economically, socially and technologically interdependent world the threat of the emergence of a cascade, i.e. of a chain of destructive processes with unpredictable outcomes is growing, since as any 'end result' may provokes a disturbance of the balance of any SBT-system which seems are in a relative equilibrium, and so on and so forth.

How to date a moment of the transformation of the Biosphere into the global SBT-system? - It is an open question because the carrying capacity of the Biosphere is not yet well-defined (calculated), at least for the reason that it is a part of more wide (cosmic) system which, in turn, is permanently expanded. A general answer may be as following: It may happen only when the feedback of such transformation would be all-embracing as well. But recently we could observe regional fluctuations of weather (extra-strong and long-term rains, tornados, unexpected rise of the temperature of surface waters of the World Ocean like the El Niňo effect). But we should keep in mind that the relationships of the Biosphere and the global SBT-system are not linear. The transformation in question may have cumulative or even destructive effect. Recently, the prevalence of technocratic thinking, that is social constructivist one has an all-embracing character but not only for the reason of its profit-making role. 
Two other features of this mode of thinking and doing are potentially dangerous as well. The former is a conviction of a majority of modern society that the process of reproduction and expansion of a consumer mode of living is endless. But the more living areas are turned into resource ones the less the Biosphere is stable. A consumerism as an ideology and the idea of sustainable society are incompatible. The latter is that the consumerism as a way of life is a totally socially-constructed phenomenon with no limits whereas sustainable society needs a very thrifty coordination of a lot of metabolic processes inside and outside the Biosphere. So there are two variants of sustainability maintaining, either we should follow an evolutionary formed structures and processes or the global SBT-system should be reconstructed into totally socially-constructed, i.e. artificial system.

\subsection{Interdependence of Macro and Micro Processes}

One more distinguishing feature of the Fourth TR is that the significance of macro and micro forces (actors) has become much more relative. Recently, even micro-changes may provoke global risks. I mean the principle of 'the force of a weakness' which is becoming now a permanent political issue. Under the weak ones I mean not only hackers or bombers alone but viruses as well as the attacks of masse of people or insects (for example, of the locust). Therefore, the trajectories of the global SBTdynamics cannot be fully predictable. The relationships between micro and macro-dynamics of such complex systems is the least investigated realm of the SBT-dynamics. Uncontrolled technological development of the most advanced countries is 'counterbalanced' by the less developed ones which use such 'defensive measures' as the bribery (graft), hacking, stealing of technological innovations and secrets, etc. In the run of such all-embracing struggle a contradiction between a declared striving for sustainable development and predictable global situation and an actual struggle for resources and geopolitical domination by global stakeholders is only growing.

The other side of the above interdependence is matter a well. In traditional and industrial societies macro and micro processes of socialization have been divided in time and space. A family, local community or clan was the main milieu for socialization of a child and a teenager for a long time. Under the Fourth TR we are dealing with the process of early socialization by means of direct including in global social networks.

\subsection{Is an era of the Internet of Things coming?}

Increasing speed of technological development means the domination of socially-constructed SBTsystems including such mental phenomena as values, aims, priorities, and types of living standards over historically-shaped types of the means of production, value systems and, customs and traditions. This domination is provided and enhanced by a growing force of the 'fourth power' governed by global stakeholders. A process of resettlement of people into a virtual world is profitable to these stakeholders. It seems that the further the more a behavior of social systems and individuals will be directed and governed by systems of social networks and not by social order and mutually accepted rules and norms. But such break with the Biosphere's regime of functioning provokes new global risks.

There are two more contradictory trends within the global SBT-system. On the one hand, in order to lessen its pressure on the Biosphere's evolutionary formed turnover the humanity is striving for minimization the use of energy and other resources. On the other hand, the growth of uncertainty of activity of various hybrid systems forces the humanity to spend more and more resources for their sustainability, security and geopolitical domination. It means that the task of re-orientation of sciences and practices for more careful study of socially-constructed and human-governed global SBT-system has become very urgent. Since the new challenges are permanently emerging here and there the interplay of scientific recommendations, practice, government and monitoring should be constantly maintained.

The ideologists of the Fourth TR see the coming of era of the 'Internet of Things' as unavoidable global trend despite its obvious risks and losses. Any so-called alternative source of energy could potentially to undermine an energetic balance of our planet. For example, a continuous use of gas and oil as energy resources may disturb atmospheric processes and generate a global warming. The consequences of global nuclear war inevitably generate a phenomenon of the 'nuclear winter', etc. Therefore, a humanitarian thinking should be revitalized and opposed to a total domination of technocratic one. Otherwise, we'll get a real 'Internet of Things' without the humanity at all. As 
Russian newspaper reported, president of Alibaba group J. Ma speaking at the meeting with the students of Moscow State University said that we have new technologies and you have talented people. Does it mean that the division on creators and rank-and-file people will continue?

\subsection{Science-Practice Integration}

In 1920-30s, Russian biophysicist A. Chizhevsky revealed the impact of solar energy fluctuations on biological processes on the Earth including such macro and micro processes as mass behavior of people and even on microstructure of a human blood [Chizhevsky 1926]. In 1970s the group of researchers guided by Dennis Meadows launched a set of long-term international research projects known as the reports for the Rome Club [Meadows et al., 1973; Meadows et al., 1989, etc.]. Unfortunately, this fundamental international project and the UNESCO's 'Man and the Biosphere' intergovernmental program have no geopolitical results.

In the run of next 25 years under the pressure of the Fourth TR global geopolitics has become more and more technocratic-oriented. To my mind, this shift has been resulted in the shaping of qualitatively new global and very dynamic system i.e. the global SBT-system. If I am right this shift requires investigation of global dynamics interdisciplinary and empirically that has been made in the late 1980s focusing in particular on the interplay between a bio-metabolism and techno-metabolism within the Biosphere [Boyden 1988]. But this very promising geopolitical idea had not yet been conceptually well comprehended.

Recently, global stakeholders and world scientific community are mainly concerned with geopolitical conflicts, population growth, poverty and global warming. But as the historian L. White [1967] had clearly showed 50 years ago, the state of natural environment is strongly dependent on a kind of human civilization. For example, in the old days the climate of the lands of the Mesopotamia had been much more suitable for rural economy and human life. But later on due to the decay of this type of civilization the majority of the Mesopotamia lands gradually turned into the desert. Thinking in more general terms, I'd say that the growing of planet's population, the shaping of primitive or/and radical civilizations and their intensive migration across the world had turned some agricultural economies initially adapted to local natural ecosystems into the waste-lands. In a manner, this thesis is correct nowadays when massive migrants' flow from Africa and the Middle East to the European Union is threatening to destroy fragile man-environment equilibrium of over-populated and densely-built European sub-continent. In such cases the unqualified migrants' labor force is simply used as 'technological material' by the developers and other agents of global market economy. Their motivation is clear: To minimize expenses for construction and other businesses and to gain maximum profit.

To my mind, the first true global environmental project had been 'The Limits to Growth' initiated and implemented by world interdisciplinary group guided by young the US scientists D. Meadows. The very idea to develop such huge project belonged to prof. J. Forrester world-known specialist in world dynamics from the US Massachusetts Technological Institute [Forrester 1969, 1971]. It's important that this long-term project (about eight reports and numerous conferences and workshops) had been supported by a business community and rich philanthropists called the Roma Club. In spite that this project has no practical results prof. D. Meadows continues his work up to now. It's indicative that one of the reports had been dedicated to the issue of a value problem in this overpopulated world.

Why I see the 'Limits to Growth' approach is not fits to new world situation? It doesn't mean that the Meadows and his team project is an old-fashioned. By no means! The matter is that the humanity has become so mighty that it began to correct or even to transform an evolutionary process. A population growth is stillac companied with poverty, illiteracy and unemployment and these issues are still of a great significance. But from my geopolitical concept which considers the planet as the global SBTsystem, such approach is important but insufficient. Besides, from the beginning of globalization era (I mean the WWI) global scientific community is still in-between: either it serves to a militaryindustrial complex to create more and more mighty weapons for mass destruction or part of it tries to warn the humanity about the coming Apocalypse.

\subsection{Geopolitical Role of Grassroots Activism}

Keeping in mind the experience of a long-term Russian environmental activism, I'd say the following. First, during half-a-century the goals and practice of grassroots is radically changed. In 90 per cents 
they are now not the street protestors but well-educated and trained professionals armed with modern geopolitical knowledge and practical experience of participation in political battles. Second, it is rather important that the grassroots movement is compiled from two polar cultures, the urban and rural ones (more exactly, from a 'center' and 'periphery' cultural milieu). Such mixt gives a positive effect: the interests of this grassroots movement covers almost total political field of modern geopolitics, from local to global. Third, Russian grassroots leaders understood that an environmental, i.e. complex education and practice should start as early as possible at least from primary schools and beyond them.

Fourth, it means that these young eco-activists have acquired the foundations of local environmental geopolitics from the very beginning not in classes but in the run of their life in industrial towns and small settlements in which ecological situation is much more worse than in the capitals. And what is more important that a majority of young such activists continues this type of activity throughout their life. I've a lucky chance to observe this process in the run of the last 30 years. Fifth, graduating from the universities they usually have no problem with job because they have already been well-educated and practically trained interdisciplinary specialists. I know tens of such specialists who oscillated between desk-work in an office and field-work as grassroots activists [Yanitsky 2005]. By the very nature of their profession they cannot avoid political activity, often with a great personal risk. Sixth, that is why these young and matured activists are concerned with such political issues as global warming, defoliation of tropical forests, large forest fires, energy and other resources saving, industrial and urban wastes and so on and so forth.

Seventh, the grassroots activism is hard to stop or to destroy because it is network-structured. The political scientists knew that many political parties have emerged from social movements including the Greens ones. For example, the Climate Action Network is a worldwide network of over 1100 NGOs in over 120 countries aimed at to stimulate the governments, business and individuals to limit human-induced climate changes. Another example: the 'Rivers without Borders', a small international group of environmentalists but with globally-embracing network which in collaboration with other NGOs has been capable to stop one of the state's projects. Eighth, earlier I tried to estimate a political stand of various groups of Russian environmental movement. In 1970-2000s there were about six political orientations: environmentalists as such, traditionalists, eco-anarchists, eco-socialists, alternativists, and technocrats [Yanitsky, 2012]. But the more the world has been globalized the more these distinctions have become relative. The reason is realization that in modern highly integrated world all environmental issues are complex and therefore subjected to interdisciplinary and multipolitical analysis. Ninth, the environmentalism is a new type of social and political thinking and mode of behavior: to see local as a part of global issues and vice versa is its distinguishing feature. Tenth, being very flexible and mobile a network-structured environmental activism sometimes wins in the struggle with so mighty institutions as the World Bank. This success is going hand in hand with overall global trend of political sociology toward a study of informatization processes as a type of state-citizen-market relations [Boudreau and Davis 2017; Davis 2017]. As D. Davis argued, 'instead of a priori ascribing an undesirable normative character to informality, its presence should be seen as an opportunity for understanding the conditions under which multiple forms of claims-making, democracy, and justice are materialize..., informality serves as an underexplored but critical analytical point of departure for theorizing governance, citizenship, and social order' [Davis 2017: $315]$.

\section{8. 'Ideal Cities' as Geopolitical mean for Representation of a Future}

There are two means of representation of an 'ideal future' of humanity: to construct a model of an ideal city and to invent the means preventing global environmental disaster. The first one had been widely used for years beginning from 'The San City' of T. Campanella. The 'Cities of Tomorrow' [Mizhuev 1916; Howard, 1898], Soviet 'green city' of the 1920-30s [Barshch and Ginzburg 1930], 'A new element of Human Settlements' [Gutnov and Lezhava1966], 'Ecopolis' [Brudnyi and Kavtaradze1981]'Neom', an ideal city of the future projected by Saudi Arabia on the Red Sea shore and so on. The ideal cities' modelling of tomorrow played and continued to play very important political and cultural role. Such modelling fulfills a set of important political functions, real and symbolic. First, during a development of such models the researchers and constructors mobilize their intellectual and social potential. Second, usually these models have been constructed to show their fitness to environmental and other requirements. Third, these models are aimed to generate public 
discussions in which outstanding professionals and public figures are usually involved. Fourth, by designing such models national power structures demonstrates its adherence to democratic values and norms, especially if such projects would be designed by an international team. Fifth, simultaneously the power elite show its peaceful attitudes and will to collaborate with other countries and research groups. In any case, the making such futurist projects is rather profitable social business because it generates new ideas and resources. It is also a political business which brings to a nation-state and its officials a publicity and weight on the world geopolitical arena. Finally, participation in such international projects brings to its participants and discussants publicity irrespectively of further faith of a particular project and its participants. In addition, such projects remained one of focal points in human history.

But the transition to the TR-4 means first of all total digitalization of geopolitics and accordingly shift towards a virtual ideal city that is to a set of mobile virtual communities. Therefore, the journalists', including criminal reporters (muckrakers) investigations are interesting but not significant. The relationships between robots and society came to the first lines of geopolitical agenda.

\section{CONCLUSiOnS}

The geopolitics as a science and practice is now in transition because they are dealing with a qualitatively new subject matter: the global SBT-system. On the first glance, the global geopolitics is contained of separate actions: the decisions, technical constructions, agreements, etc. But actually the modern geopolitics is inherently integrated by metabolic processes. U. Beck was right saying that the distinguishing feature of modern world is the side-effects.

Global geopolitics is in the process of transition towards all-embracing and mobile socio-political process. Such geopolitics should be interdisciplinary and multi-sided, that is it should be flexible, capable to foresee coming threats, adapt to them, and to mitigate possible changes and emergences may happen. A mutual understanding between politicians and environmentalists and the capability to translate the results of their mutually-developed recommendations and decisions to practitioners is of a primary importance. Speaking more generally, global environmental geopolitical language should be understandable for all parties involved. As coming climate change shows modern geopolitics has to pay much more attention to man-environment relationships. On the one hand, the geo-politicians has to know more about social and political effects of global warming and other 'boomerang effects' of men's interference into natural processes and ecosystems. On the other hand, these politicians should learn more about limits of such interference.

Geopolitical 'wars' are unavoidable in foreseeable common future. After half-a-century struggle of global scientific and grassroots community of politicians and environmentalists for more sustainable global future, it is clear that world institutions like the UN and many others cannot solve this global issue. Amutual trend to use natural forces including man-made natural disasters as a weapon is continued. The reverse side of the same coin is mass migrant's flows across the globe. What has to be done? I see at least three instruments that should be used simultaneously. We must diminish humanity's interference into natural ecosystems and processes as much as possible. We should diminish an expansion of consumer way of life. The latter process has two interrelated sides: the efforts to limit appetites of the reach and of the growth of living standards of the poor. The geopolitics should work hand-in-hand with sociologists and economists because geopolitical calamities affect first of all rank-and-file people and those fragile ecosystems which cannot newer be rehabilitated.

Then, as one can see, modern geopolitics is less and less based on existing international institutions and more on temporal agreements, endless talks and on the road maps. If we accept this shift as unavoidable, overall structure of these institutions should be reconsidered. It seems that these institutions should be supplied by the system of permanent global monitoring. Anyhow, the gap between the tempo-rhythms of current global events and the pace of institutional reflection on them must be to overcome.

As to science, the imperatives are the same: close interdisciplinary contacts between social, natural and technical sciences; focus on the metabolic processes including socio-political metabolism as such; collaboration of academics with grassroots and environmental movements in various parts of the world; and to make geopolitical effects more understandable to ordinary people. In our unstable and risky world a democracy cannot be reduced to electoral processes. A growing amount of fake news in 
the media should be gradually replaced by systemic geopolitical Enlightenment and independent control.

Concerning the models of ideal cities, it should be said that such cities as a best mean for representation of a future for all strata of a society. In particular, the Soviet cities of tomorrow of the 1930-70s had substantial socio-political effect because they had simultaneously been the manifestos and possible models of a socialist way of life. In particular, public discussions between the urbanists and des-urbanists, adherents of collective and individualized everyday life [Gradov 1968; Kogan 2003; Meerovich 2007] played a role of testing ground for various modes of eco-social planning of the coming new wave of modernization. Human history shows thata persistent labor of scientists and practitioners always takes over political time-servers. The world population is very sensitive to any changes in urban politics because it directly influences their habit of everyday life.

The abovementioned global transformations urge us to make serious changes in the processes of education and training. The only one way to meet the above risks and threats is to launch a substantial 'renovation' process in socio-political spheres as such, especially in the process of early socialization. It is going on about the shift from subject-oriented to problem-oriented methods of teaching and training. Children and teenagers have to understand that our world is an inseparable whole. The ecological approach to geopolitics is very low but still shaping.

\section{REFERENCES}

[1] Barshch M. and Ginzburg M. 1930.ZelenyiGorod [A Green City]. Sovremennaya Architectura, No 1-2: 212.

[2] Bartelson J. 2000. Three concepts of Globalization. International Sociology, Vol. 15 (2): 180-196.

[3] Beck U. 2000.World Risk Society. Malden, MA: Polity Press.

[4] Boudreau J.-A., Davis D.E. 2017. Introduction: A processual approach to informatization. Current Sociology Monograph, Vol. 65 (2): 151-166.

[5] Boyden S. 1988. Biosocial Science and Integrative Approaches to Research and Planning, in: Cities and Ecology. The International Expert Meeting on Ecological Approaches to Urban Planning, Vol. 1. Moscow: Center of International Projects: 75-84.

[6] BrudnyiA. And KavtaradzeD. 1981،“"Ecopolis".VvedeniyeiProblemy. ["Ecopolis": Introduction and Issues]. Mimeo. Pushchino.

[7] Castells M. 1996. The Information Age. Economy, Society and Culture. Oxford: Blackwell Publishers, Ltd.

[8] Chizevskiy A. 1926.FizicheskieFaktoryIstoricheskogoProcessa [Physical Factors of a Historical Process]. Kalyga: Pervayagostipolitografiya (in Russ.).

[9] Davis D.E. 2017. Informality and state theory: some concluding remarks. Current Sociology Monograph, Vol. 65 (2): 315-324.

[10] Della Porta D. and Diani M. 2006.Social Movements. An Introduction.2nd.ed. Malden, Mass: Blackwell.

[11] Diani M. and McAdam D., eds. 2003. Social Movements and Networks. Relational Approach to Collective Action. Oxford: Oxford University Press.

[12] Fisher-Kowalski M. and H. Haberl.2007. Socio ecological Transitions and Global Change. Trajectories of Social Metabolism and Land Use. Vienna: Klagenfurt University.

[13] Fisher-Kowalski M. (1997) Society's Metabolism: On the Childhood and Adolescence of a Rising Conceptual Star, in:Redklift M. and G. Woodgate, eds. The International Handbook of Environmental Sociology. Northampton, MA: Edward Elgar. Pp.119-137.

[14] Forrester J. 1969. Urban Dynamics. London: The M.I.T. Press.

[15] Forrester J. 1971. World Dynamics. Cambridge: Wright-Allen Press.

[16] GradovG. 1968. Gradostroitel'stvoi but [Urban Planning and a mode of living].Moscow: Stroiizdat.

[17] GutnovA. andLezhavaL. 1966.Novyi element rasseleniya: naputi $k$ novomygorodu [New element of city planning: Towards a New City]. Moscow: Stroiizdat.

[18] Haberl H., Fisher-Kowalski M., Krausmann F. and Winiwater V., eds. 2016. Society-Nature Relations across Time and Space. Available at: http://link.springer.com/book/10.1007\%2F978-3-319-33326-7

[19] Howard E. 1902. The Garden Cities of Tomorrow. London.

[20] Keen D. 2008.Complex Emergences. Cambridge: Polity.

[21] KoganL. 2003. Gorodaipolitika: Rossiiskiyeuroki [Cities and Politics: Russian Lessons]. Obninsk: Institut Munitsypal'nogo Upravleniya. 
[22] Mackinder H. 1919. Democratic Ideas and Reality: A Study in the Politics of Reconstruction. London: Constable.

[23] Magnusson W. 2011. Politics of urbanism: Seeing Like a City. Abingdon: Routledge.

[24] Meadows D.L. and Meadows D.H., eds. 1973.Toward Global Equilibrium. Cambridge, Mass.: WrightAllen Press.

[25] Meadows D.H., Meadows D.H., Randers J.W. 1989.The Limits to Growth.A Report for the Club of Rome's Project on the Predicament of Mankind. 2nd ed. N.Y.: Universe Books.

[26] MeerovichM. 2007. RozhdeniyeiSmert' SovetskogoGoroda-Sada[A Birth and the Death of a Soviet Garden-City], in:VestnikEurasii.Availableat: www.archi.ru/lib/e_publication_for_print.html?id

[27] Mizhuev P. 1916.Sady-GorodaiZhilishchnyiVopros v Anglii[Garden-cities and a Habitat in England]. Petrograd: 'NovoeVremya'.

[28] MilyutinN. 1930. Sotsgorod. Problem astroitel'stvasotsialisticheskichgorodov [ASocialist City. An Issue of Construction of Socialists Cities]. Moscow and Leningrad: Gosizdat. Available at: http://rutracher.org/forum/ viewtopic.php?t=4530713

[29] Sabsovich L. Gorodabudushchegoi organizatsiyasotsialisticheskogobuta [Future Cities and Organization of a Socialist Life]. Moscow: Gostechizdat.

[30] Robertson R. 1994. Globalization. Social Theory and Global Culture. London: SAGE Publications.

[31] Schwab K. 2016. The Fourth Industrial Revolution. Geneva: World Economic Forum.

[32] Sennett R. 1970.The Uses of Disorder: Personal Identity and City Life. New York: Knopf.

[33] The Global Risks Report 2016. Geneva: World Economic Forum. Available at: www.weforum.org/risks

[34] Toffler A. 1970. Future Shock. N.Y.: Random House.

[35] Urry J. 2008.Mobilities. Cambridge: Polity Press.

[36] Urry J. 2011.Climate Change and Society. Cambridge: Polity Press.

[37] Vernadsky V. 1980. (first ed. 1922). Problemybiogeochimii. Trudy biogeochimicheskoilaboratorii. Vypusk XVI. Moskva: Nauka [Geochemical problems. Works of Biogeochemical Laboratory]. Issue XVI, Moscow: Nauka.

[38] White L., Jr. 1967.The Historical Roots of Our Ecological Crisis.Science, Vol. 155, pp. 1203-1207.

[39] Yanitsky O. 2005. Dialogue between Science and Society.Social Sciences.A Quarterly Journal of the Russian Academy of Sciences Vol. 36, No 2: 78 - 90.

[40] Yanitsky O. 2012. From Nature Protection to Politics: The Russian Environmental Movement 1960-2010. Environmental Politics. 21 (6): 922-940.

Citation: YANITSKY Oleg Nikolaevich. "Ecology as a Global Geopolitical Issue". International Journal of Political Science (IJPS), vol4, no.1, 2018, pp.43-52. doi:http://dx.doi.org/10.20431/2454-9452.0401005.

Copyright: (C) 2018 Authors. This is an open-access article distributed under the terms of the Creative Commons Attribution License, which permits unrestricted use, distribution, and reproduction in any medium, provided the original author and source are credited. 